\title{
Development and Validation of an HPLC- UV Method for the Determination of Melphalan from Lyophilized Nanosuspension
}

\author{
Powar Trupti Ashok*, Hajare Ashok Ananda \\ Department of Pharmaceutics, Bharati Vidyapeeth College of Pharmacy, Near Chitranagari, Kolhapur, Maharashtra- 416013, INDIA.
}

\begin{abstract}
Aim and Objective: The objective of this work was to develop and validate a high performance liquid chromatography (HPLC) method for the quantitative analysis of melphalan, an anticancer drug from lyophilized nanosuspension. Material and Method: Chromatographic separation was achieved by using a reverse-phase $C_{18}$ column (150 $\mathrm{mm} \times 4.6 \mathrm{~mm}$, pore size $5 \mu \mathrm{m}$, Phenomenex). The mobile phase was optimized as acetic acid, water and methanol (1: 49.5: 49.5) with $\mathrm{pH} 4$ at a flow rate of $1 \mathrm{~mL} / \mathrm{min}$. The melphalan was detected and quantitated using a UV detector at a wavelength of $254 \mathrm{~nm}$. Result: The method was shown to be specific and linear in the range of $10-50 \mu \mathrm{g} \cdot \mathrm{mL}^{-1}$ with correlation coefficient of 0.9979 and was precise at the intra-day level as reflected by relative standard deviation, accurate at recovery rate $99.75 \pm 0.08$ and robust to change mobile phase and column brand. The detection and quantitation limits were $0.2956 \mu \mathrm{g} \cdot \mathrm{mL}^{-1}$ and $0.5874 \mu \mathrm{g} \cdot \mathrm{mL}^{-1}$, respectively. The proposed method could be advantageous in estimation of melphalan quantitation in lyophilized nanosuspension form in the presence of excipients. Conclusion: The method was found to be simple, specific, rapid, precise, accurate and reproducible. The method was successfully applied for determination of the entrapment efficiency of melphalan from lyophilized nanosuspension and was found to $93.56 \pm 4.32 \%$.
\end{abstract}

Key words: Melphalan, HPLC, Lyophilized nanosuspension, Entrapment Efficiency, Precision, Accuracy.

\section{INTRODUCTION}

Melphalan (Alkeran) is chemically termed as 3-(P-(Bis (2-chloroethyl) amino) phenyl)$\mathrm{L}$-alanine, an antineoplastic agent, belonging to the class of nitrogen mustard alkylating agents. ${ }^{1}$ Its a bifunctional alkylating agent active against multiple myeloma, malignant melanoma, ovarian carcinoma and lymphomas. The molecular formula of melphalan is $\mathrm{C}_{13} \mathrm{H}_{18} \mathrm{Cl}_{2} \mathrm{~N}_{2} \mathrm{O}_{2}$ and its molecular weight is 305.20. ${ }^{2}$ The structural formula of melphalan was depicted in Figure 1. Melphalan is an active L-isomer, first synthesized in 1953 by Bergel and Stock, ${ }^{3}$ while the D-isomer form is less active and requires high dosage for effect on chromosomes. The racemic (DL-) form of melphalan is known as sarcolysin. ${ }^{4}$ Melphalan is insoluble in water while its hydrochloride salt form is soluble with $\mathrm{pKa} 1$ of $~ 2.5$. Melphalan hydrochloride injection was supplied as a sterile, non-pyrogenic, freeze-dried powder, which can be reconstituted using sterile diluents before injection. ${ }^{2}$ Method development is a multi-step process, which involves adoption of existing method and making minor changes that are suitable for the novel application as well as developing a HPLC method for the estimation of drug. Method validation is a process which is normally followed for acceptability of an analytical techniques used to determine drugs in pharmaceutical dosage forms. ${ }^{2}$

Literature suggests use of some chromatographic methods and Mass spectroscopy
Submission Date: 05-07-201; Revision Date: 29-09-2018; Accepted Date: 18-01-2019

DOI: 10.5530/ijper.53.2.40 Correspondence: Powar Trupti Ashok, Department of Pharmaceutics, Senior Research Fellow, Bharati Vidyapeeth College of Pharmacy, Near Chitranagari, Kolhapur, Maharashtra, 416013 INDIA.

Phone: 9766196512

E-mail: truptipowar51@ gmail.com

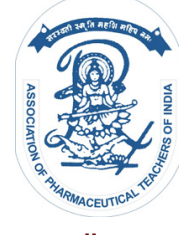

www.ijper.org 


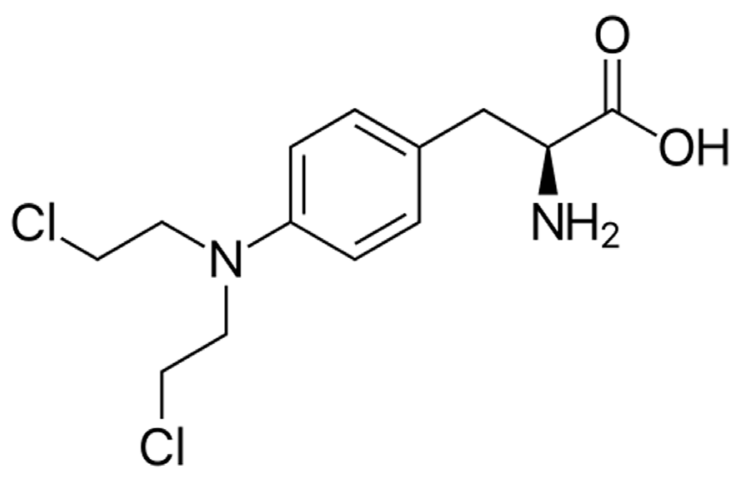

Figure 1: Chemical structure of Melphalan.

methods for the estimation of melphalan in pure drug and pharmaceutical dosage forms like tablet and injectables. Researchers had developed reverse phase HPLC and UV method to determine the melphalan from tablet and injection dosage form. The validated results proofed that developed method was reliable and can be preferred for routine analysis of melphalan from different dosage forms..$^{5-6}$ Many researchers also validated stability of melphalan via degradation pathway in different stress conditions like acid, bases, force oxidation and hydrolysis etc., using reverse phase liquid chromatographic method. ${ }^{7}$ Further robust gradient high performance liquid chromatographic (HPLC) technique was also used for simultaneous determination of melphalan and its related impurities. ${ }^{8} \mathrm{UV}$ and HPLC methods were also developed and validated to determine the drug loading capacity of layer by layer magnetic nanoparticles of Methotrexate and Melphalan. ${ }^{9}$ Melphalan was also detected from biological samples using LC-MS or HPLC or both the chromatographic methods. ${ }^{10}$

When developing a nanosuspension it is essential to use an analytical procedure that allows optimal determination of the drug entrapment efficiency thereby enabling to assure that all the drug has been adequately extracted from the drug delivery system. ${ }^{11}$ Taking all in consideration, the objective of present work is to develop and validate a new analytical method for quantification of melphalan from lyophilized nanosuspension. The newly developed method is based on HPLC with UV detection being rapid, simple and easy to apply in routine pharmaceutical analysis. In this paper the method is developed using both freshly prepared batches and stored samples of melphalan lyophilized nanosuspension.

\section{MATERIAL AND METHODS}

\section{Chemicals and Reagents}

Melphalan drug was purchased from Beijing Mesochem Technology Co., Ltd. China. HPLC grade methanol was procured from Thermo Fisher Scientific Pvt. Ltd.
Mumbai, India. Acetic acid was procured from Merck specialities Pvt. Ltd. Mumbai, India. Double distilled water was prepared in laboratory. The mobile phase was filtered through $0.45 \mu \mathrm{m}$ Millipore membranes (Millipore Corp., Madrid, Spain) and was degassed by ultra-sonication for $20 \mathrm{~min}$ before use.

\section{Instrumentation}

For the development and validation of the HPLC method, Shimadzu Corporation, Tokyo, Japan equipped with PU 2080 Pump and UV 2075 Detector was used. The data were analyzed using JASCO BROWIN (version 1.50, build 16) software.

\section{Chromatographic condition}

The analysis was carried out using a Phenomenex $\mathrm{C}_{18}$ $(150 \mathrm{~nm} \times 4.6 \mathrm{~nm}$, i.d., $5 \mu \mathrm{m}$ particle size $)$ a reversed phase analytical column. Throughout the analysis, the column was held at $25.0 \pm 0.5^{\circ} \mathrm{C}$. Chromatographic analysis was performed by using mobile phase consisting of Acetic acid: Methanol: Water (1: 49.5: 49.5) adjusted to $\mathrm{pH} 4$, which was then pumped through column at a flow rate of $1 \mathrm{~mL} \mathrm{~min}{ }^{-1}$ and the quantification was achieved at $254 \mathrm{~nm}$. The mobile phase was vacuum-filtered through $0.45 \mu \mathrm{m}$ nylon Millipore membranes (Millipore Corp., Madrid, Spain) and was degassed by ultra-sonication for $20 \mathrm{~min}$ before use. The mobile phase was pumped through the chromatographic column at a flow rate of $1.0 \mathrm{~mL} \mathrm{~min}^{-1}$, the injection volume was $20 \mu \mathrm{L}$ and UV detection was performed at $254 \mathrm{~nm}$. Each test required 15 min.

\section{Standard and sample solutions preparation}

Standard stock solutions of melphalan $\left(1 \mathrm{mg} \mathrm{mL}^{-1}\right)$ were daily prepared by dissolving the appropriate amounts of the drug in methanol. The solutions for calibration curves were prepared by spiking the standard stock solutions to yield concentrations ranging between 10-50 $\mu \mathrm{g} \mathrm{mL} \mathrm{m}^{-1}$ and were prepared in the mobile phase.

\section{Validation procedure}

The validation of optimized chromatographic method was performed according to the Q2 (R1) guidelines of International Conference on Harmonization (ICH, 2005). The following characteristics like specificity, linearity, range, accuracy, precision, detection limit (DL), quantitation limit (QL) were considered for validation. Precision was evaluated by repeatability (intra-day) and intermediate precision (inter-day). ${ }^{10-12}$

\section{Linearity}

Calibration curves of melphalan were obtained by serial dilution of standard stock solution for five different 
concentrations $\left(10,20,30,40\right.$ and $\left.50 \mu \mathrm{g} \mathrm{mL}^{-1}\right)$ by considering drug purity as $99.4 \%$ respectively, as indicated by the manufacturer. The solutions were injected thrice into HPLC column, keeping injection volume constant $(20 \mu \mathrm{L})$. Each calibration curve was analysed by plotting peak area ratio of melphalan against nominal concentration of standard solution. The linearity was determined by calculating regression line from the peak area $\mathrm{v} / \mathrm{s}$ concentration plot for five standard solutions using linear least squares methodology and by analysis of the respective response factors (i.e. peak area divided by concentration of each standard sample). Range was derived from linearity, accuracy and precision studies.

\section{Precision}

The precision of the method was determined by instrumental precision, repeatability (intra-day) and intermediate precision (inter-day). Precision was expressed as relative standard deviation (\% RSD) and relative error (RE) and was evaluated by analysing sets of three melphalan standard samples of 10,30 and $50 \mu \mathrm{g} \mathrm{mL}^{-1}$ on the same day and on three consecutive days. The concentrations selected correspond to low, mid and high levels of the calibration curves.

\section{Accuracy/recovery}

An analytical method, accuracy is the closeness of the test results obtained by the method to the true value. Accuracy was evaluated at three concentration levels of melphalan (10, 30 and $\left.50 \mu \mathrm{g} \mathrm{mL}^{-1}\right)$ and was analyzed in centuplicate on the same day and on three consecutive days. Recovery was determined from the found concentration with respect to the one added, being evaluated in terms of relative standard deviation (\% RSD).

\section{Sensitivity}

Sensitivity of the method was determined by means of the detection limit (LOD) and quantification limit (LOQ). LOD is the lower concentration of analyte that can be detected and LOQ is the lowest concentration of analyte that can be quantified with suitable precision and accuracy. Calculations for LOD were based on the standard deviation of the y-intercept of the regression line $(\sigma)$ and the slope of the line $(\mathrm{S})$, using the equations according to the IUPAC criteria,

$$
\mathrm{LOD}=3.3 \times \sigma / \mathrm{S}
$$

LOQ was calculated by means of the equation,

$$
\mathrm{LOQ}=10 \times \sigma / \mathrm{S} \quad \text { Eq. (2) }
$$

Once LOQ was calculated, three samples were freshly prepared with concentrations equal to LOQ and then analyzed by the HPLC method developed on three consecutive days.

\section{Robustness}

Robustness was determined by analysing different experimental factors such as $\mathrm{pH}$ of mobile phase, composition of the mobile phase and flow. The choice of the factors tested for robustness of the method was based upon our previous experience in method optimisation. Methanol (\%) in the mobile phase was assayed with a $\pm 10 \%$ variation, column oven temperature with a $\pm 1^{\circ} \mathrm{C}$ variation, $\mathrm{pH}$ of the mobile phase with a variation of \pm 1 units and flow rate with $\pm 0.25 \mathrm{~mL} \mathrm{~min}^{-1}$ variation. The effects of these experimental conditions on retention times, repeatability of the method and recoveries $(\%)$ were tested.

\section{Stability}

Stability was evaluated by analysing melphalan standard samples $\left(50 \mu \mathrm{g} \mathrm{mL}^{-1}\right)$ at room temperature and after freeze conditions for $24 \mathrm{~h}$ for 15 days, respectively. The results obtained are compared to those freshly prepared samples. In addition, the stability of the method was verified by exposing three melphalan samples $(50 \mu \mathrm{g}$ $\mathrm{mL}^{-1}$ ) to sunlight at room temperature for $24 \mathrm{~h}$ in order to reproduce standard manipulation conditions. The analyte was considered stable under test conditions if changes obtained were within $\pm 2 \%$.

\section{Specificity}

Method specificity was evaluated through possible interference due to the components of the lyophilized nanosuspension. Three different samples of mannitol, blank lyophilized nanosuspension, blank lyophilized nanosuspension spiked with a solution of melphalan $\left(50 \mu \mathrm{g} \mathrm{mL}{ }^{-1}\right)$ were prepared and then analyzed by the HPLC method proposed using the extraction procedure of melphalan from lyophilized nanosuspension.

\section{Preparation of lyophilized nanosuspension of melphalan}

Melphalan nanosuspension was prepared by high-pressure homogenizer (HPH). To prevent blocking of the homogenizer valve, the coarse powder of EE was first dispersed in an aqueous solution of stabilizer using an UltraTurrax T25 Jahnke and Kunkel, Staufen, Germany) at $8000 \mathrm{rpm}$ for $1 \mathrm{hr}$ to form prenanosuspension. The prenanosuspension was then processed through a high-pressure homogenizer Panda PLUS 2000 (GEA Niro Soavi, Germany) with two homogenization cycles at 150, 500 and 1000 bars, followed by several cycles at 1500 bar. Nanosuspensions of different particle sizes were prepared by varying the number of homog- 
enization cycles applied. The process temperature of $\mathrm{HPH}$ was kept constant at $25^{\circ} \mathrm{C} .{ }^{12}$ The lyophilization process was carried out using laboratory freeze dryer (Freezone12, Labconco, MO, USA). After high-pressure homogenization process, Melphalan NPs $(25 \mathrm{ml})$ and optimized cryoprotectant mannitol $(6 \%)$ was dispersed in $30 \mathrm{ml} \mathrm{semi}$ stoppered glass vials with slotted rubber closures and were frozen for $12 \mathrm{~h}$ at $-40^{\circ} \mathrm{C}$. The primary drying was performed at $-53^{\circ} \mathrm{C}$ for $24 \mathrm{~h}$ and pressure maintained $0.016 \mathrm{~m}$ Bar. The secondary drying was carried out at $10^{\circ} \mathrm{C}$ for $8 \mathrm{~h}$ followed by $25^{\circ} \mathrm{C}$ for 4 $\mathrm{h}$ by increasing the temperature at a rate of $0.5^{\circ} \mathrm{C} / \mathrm{min}$. Finally, the temperature of cold trap was maintained at $-53^{\circ} \mathrm{C}$ during the entire process. Resultant powder of MEL NPs were used future for subsequent evaluation studies. ${ }^{13-14}$

\section{Extraction recovery and determination of melphalan encapsulation efficiency within lyophilized nanosuspension:}

Extraction recovery of melphalan from lyophilized nanosuspension developed was performed by weighing $10 \mathrm{mg}$ of lyophilized nanosuspension dissolved into $1 \mathrm{ml}$ of water. The extraction recovery procedure was evaluated using different volumes of methanol (5- $20 \mathrm{~mL}$ ) to establish proposed method for complete recovery of melphalan. Once the volume of methanol to be used was established samples were centrifuged for $5 \mathrm{~min}$ at $5000 \mathrm{rpm}$. After dilution, all samples were filtered through $0.45 \mu \mathrm{m}$ filters and the melphalan content was quantified by proposed HPLC method. The entrapment efficacy (EE \%) was calculated from the ratio of the active ingredient that is encapsulated into the lyophilized nanosuspension and the active ingredient used, according the following equation:

$\mathrm{EE}(\%)=($ Amount of melphalan in lyophilized nanosuspension/Initial amount of melphalan used in the preparation of lyophilized nanosuspension) x100 Eq. (3)

\section{RESULTS AND DISCUSSION}

A new analytical procedure was developed prior to its validation phase to provide a simple, rapid, optimized and cost efficient HPLC method with UV detection for determination and quantification of melphalan in lyophilized nanosuspension. This lyophilized nanosuspension was developed for enhancing the oral bioavailability and stability of melphalan for treatment of ovarian cancer. Chromatographic conditions investigated were $\mathrm{pH}$, composition of mobile phase, column oven temperature and flow rate, the conditions that could greatly influences the separation procedure required to obtain narrow and symmetrical peaks and acceptable retention times. Here, Phenomenex $\mathrm{C}_{18}(150 \mathrm{~nm} \times 4.6 \mathrm{~nm}$, i.d., $5 \mu \mathrm{m}$ particle size) column was chosen due to its high efficiency and improved peak shape. Different proportions of mobile phase consisting acetic acid: water: methanol and $\mathrm{pHs}$ were evaluated and compared (data not shown) to optimize final mobile phase. The results obtained showed that at lower proportion of methanol $(40 \%)$ and at higher portion of water $(60 \%)$, melphalan elutes first with shorter retention time with broad, tailed and bad resolution. As the proportion of methanol and water are increased and made equal in ratio, retention time of melphalan increases and intensive peak with absence of tailing and broadening was obtained. Therefore, to achieve better chromatographic results, the composition of mobile phase played an important role. Here in this study, best results were obtained with mobile phase comprising Acetic acid: Methanol: Water (1: 49.5: 49.5) adjusted to $\mathrm{pH} 4$ (Figure 2).

This composition of mobile phase was found to provide better peak shape with lesser tailing and appropriate retention time. The retention time for melphalan from lyophilized nanosuspension was around $3.033 \mathrm{~min}$. The optimum flow rate was found to be $1.0 \mathrm{~mL} \mathrm{~min}{ }^{-1}$. Moreover, wavelength of $254 \mathrm{~nm}$ was found to be most efficient to detect and quantify melphalan in single run. The resolution of melphalan peaks were adequately resolved and thus demonstrates adequate specificity. Before analysis, the chromatographic column was equilibrated with mobile phase for $30 \mathrm{~min}$ prior to injection. During regular use of chromatographic system, its performance may vary, thereby affecting the reliability of analytical results obtained. Thus, system suitability tests were carried out to verify, whether the resolution and reproducibility of chromatographic system are adequate for analysis performed. Study of system suitability revealed that tailing factor was 1.5 and number

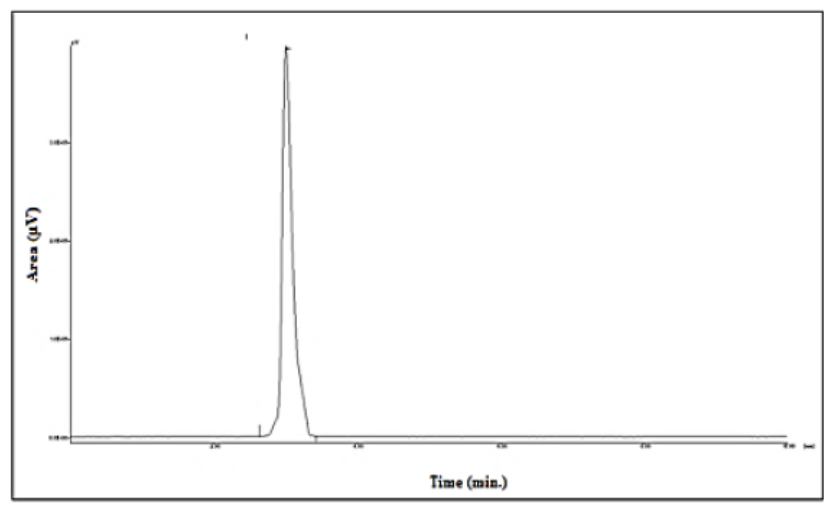

Figure 2: HPLC chromatogram of melphalan in lyophilized nanosuspension in mobile phase Acetic acid: methanol: water $(1: 49.5: 49.5)$ at $\mathrm{pH} 4$. 
of theoretical plates were 3856, all complying with the recommended limits; tailing factor $\leq 2$ and number of theoretical plates $>2000$.

To confirm that, the analytical procedure developed is adequate for its intended use method validation was performed and results derived were utilized to determine the reliability and consistency of the analytical data obtained.

\section{Linearity}

Calibration curves were obtained by plotting the peak area ratio versus concentration for melphalan. Homoscedasticity was proved by using Cochran's test. The test statistic values obtained (Ccal) for melphalan were 0.25 , smaller than the critical value which was 0.52 ,indicating that the concentration of analyte does not have an influence on the response and thus, ordinary least squares can be utilized for the estimation of the regression lines. The linearity of the method was established between 10 and $50 \mu \mathrm{g} \mathrm{mL} \mathrm{m}^{-1}$ (Table 1, Figure 3), with determination coefficients which was found to be higher than 0.99 . After ANOVA, correlation between both variables fitted a linear model (F-lack of fit test with $p>0.05$ ) and regression was demonstrated $(p<0.05)$. By means of the Student's t-test, the proportionality of the method $(p>0.05)$ for melphalan was demonstrated. Thus, results obtained therefore demonstrated a good correlation between peak area and concentration for melphalan.

\section{Precision}

For melphalan, Intra- and inter-day precision was determined by measuring six replicates of three concentration levels for three consecutive days. The results obtained are summarized in Table 2 . The $\%$ RSD values for inter-day precision ranged from 0.98 to 1.25 , which as lower than $1.8 \%$. Relative error (\% RE) was also calculated by means of the following equation:

$\% \mathrm{RE}=($ measured value-theoretical value $) \times 100 /$ theoretical value

The $\% \mathrm{RE}$ values obtained ranged between -0.090 and 0.25 for melphalan. The $\%$ RDS for intra-day precision
Table 1: Linearity of the HPLC method developed for melphalan in lyophilized nanosuspension.

\begin{tabular}{|c|c|}
\hline Statistical tools & $\begin{array}{c}\text { Melphalan in lyophilized } \\
\text { nanosuspension }\end{array}$ \\
\hline Range $\left(\mu \mathrm{g} \mathrm{mL}^{-}{ }^{-}\right)$ & $10-50$ \\
\hline Slope & 63623 \\
\hline Intercept & -58481 \\
\hline Correlation coefficient $(\mathrm{R})$ & 0.9979 \\
\hline Determination coefficient $\left(\mathrm{R}^{2}\right)$ & 0.9993 \\
\hline Theoretical plates & 3856 \\
\hline Tailing factor & 1.5 \\
\hline Retention time $(\min )$. & 3.033 \\
\hline
\end{tabular}

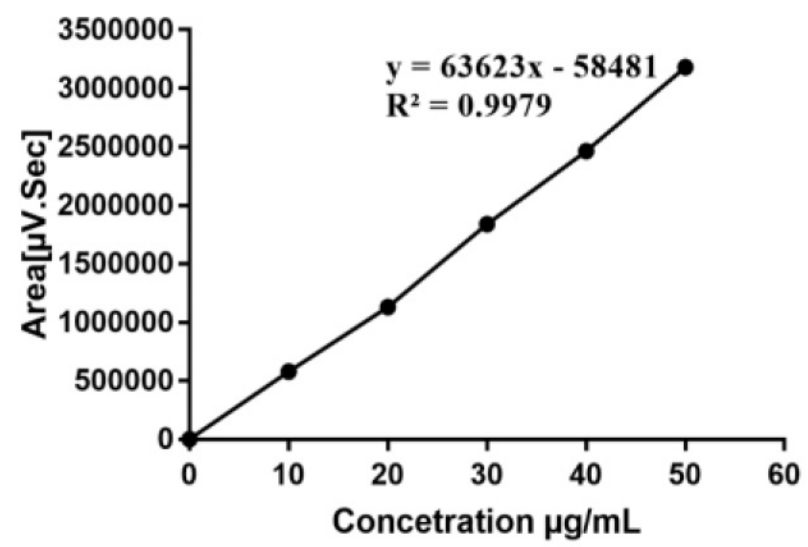

Figure 3: Calibration curve of melphalan in mobile phase.

found ranged between 0.85 and 1.16. Values obtained in all cases were lower than $1 \%$ indicating satisfactory precision for analytical method.

\section{Accuracy/Recovery}

It is suggested to collect minimum data from nine determinations over a minimum three concentration levels covering the specified range, according to $\mathrm{ICH}$ guidelines. In the experiment the concentration assayed were 10,30 and $50 \mu \mathrm{g} \mathrm{mL} \mathrm{m}^{-1}$. The statistical analysis performed for melphalan was expressed as percentage

Table 2: RSD (relative standard deviation) and RE (relative error) of the HPLC method developed for melphalan in lyophilized nanosuspension.

\begin{tabular}{|c|c|c|c|c|c|c|}
\hline \multirow{2}{*}{$\begin{array}{c}\text { Concentration } \\
\left(\boldsymbol{\mu g} \mathbf{~ m L}^{-1}\right)\end{array}$} & \multicolumn{3}{|c|}{ Intraday } & \multicolumn{3}{c|}{ Interday } \\
\cline { 2 - 7 } & $\begin{array}{c}\text { Mean recovery } \\
(\%)\end{array}$ & \%RSD & \%RE & $\begin{array}{c}\text { Mean recovery } \\
(\%)\end{array}$ & \%RSD & \%RE \\
\hline 10 & 96.14 & 0.98 & -0.15 & 97.02 & 0.85 & -0.090 \\
\hline 30 & 100.99 & 1.15 & -0.33 & 101.23 & 1.05 & -0.152 \\
\hline 50 & 99.91 & 1.25 & 0.25 & 98.87 & 1.16 & 0.089 \\
\hline
\end{tabular}


Table 3: Results of accuracy of the HPLC method developed for melphalan.

\begin{tabular}{|c|c|c|c|}
\hline \multirow[t]{2}{*}{ Concentration $\left(\mu \mathrm{g} \mathrm{mL}^{-1}\right)$} & \multicolumn{3}{|c|}{ Melphalan } \\
\hline & Recovery $\left(\mu \mathrm{g} \mathrm{mL} \mathrm{L}^{-1}\right)$ & Recovery (\%) & Mean \pm SD \%RSD \\
\hline 10 & 9.50 & 95.00 & \multirow{3}{*}{$96.47 \pm 1.56$} \\
\hline 10 & 9.63 & 96.30 & \\
\hline 10 & 9.81 & 98.10 & \\
\hline 30 & 28.56 & 95.20 & \multirow{3}{*}{$97.90 \pm 2.44$} \\
\hline 30 & 29.56 & 98.53 & \\
\hline 30 & 29.99 & 99.97 & \\
\hline 50 & 49.85 & 99.70 & \multirow{3}{*}{$99.68 \pm 0.34$} \\
\hline 50 & 49.88 & 99.76 & \\
\hline 50 & 49.65 & 99.3 & \\
\hline
\end{tabular}

recoveries of known amounts of the analytes, coefficients of variation (CVs), standard deviations and mean values, shown in Table 3. By comparing the concentration values obtained for each level with theoretical values assayed, the percentage recoveries were estimated, which are consider $100 \%$. For the three concentration levels assayed, mean recovery value obtained were close to $100 \%$ with $\%$ RSD less than $2 \%$, thus indicating low variability and strong agreement between experimental and theoretical values. The mean recoveries should be $100 \pm 2 \%$ at each concentration level according to FDA an accuracy criterion. ${ }^{15}$ In this study the confidence intervals included 100\% and Student's t-test confirmed the global mean values were not statistically different from $100 \%$.

\section{Sensitivity}

By means of the detection limit, (LOD) and quantification limit (LOQ) sensitivity of the method was determined. Based on the standard deviation of response of the calibration curve, LOD and LOQ were separately determined. In this experiment, LOD and LOQ values obtained were $0.2956 \mu \mathrm{g} \cdot \mathrm{mL}^{-1}$ and $0.5874 \mu \mathrm{g} \cdot \mathrm{mL}^{-1}$. For determination of more reliability, the accuracy of method proposed at LOQ, three samples were prepared and then assayed on three consecutive days. Mean results obtained were $2.03 \pm 0.02 \mu \mathrm{g} \mathrm{mL}$, with CVs lower than $2 \%$ for both intra- and inter-day precision. These low CV values confirm the accuracy of the new HPLC method proposed.

\section{Robustness}

Robustness should be studied in the early development of an analytical method. As per the ICH guidelines, method robustness occurs when the effects of changes in chromatographic conditions such as; flow rate $( \pm 0.25$ $\left.\mathrm{mL} \mathrm{min-}{ }^{1}\right)$, components in the mobile phase ( $\left.\pm 10 \%\right)$, $\mathrm{pH}$ of the mobile phase ( \pm 1 units) and column oven

\begin{tabular}{|c|c|c|c|}
\hline \multicolumn{4}{|c|}{ Table 4: Robustness of the method. } \\
\hline \multirow{2}{*}{ Parameters } & Value & $\begin{array}{c}\text { Mean } \\
\text { Recovery (\%) }\end{array}$ & \% RSD \\
\hline \multirow{3}{*}{$\mathrm{pH}$} & 4 & 99.10 & 0.85 \\
\cline { 2 - 4 } & 5 & 98.56 & 0.92 \\
\cline { 2 - 4 } & 6 & 100.10 & 0.96 \\
\hline \multirow{3}{*}{ Flow rate $(\mathrm{mL} / \mathrm{min})$} & 0.75 & 98.65 & 0.87 \\
\cline { 2 - 4 } & 1 & 99.96 & 0.90 \\
\hline \multirow{3}{*}{$\begin{array}{c}\text { Mobile phase } \\
(\% \text { methanol) }\end{array}$} & 1.25 & 98.56 & 0.95 \\
\cline { 2 - 4 } & 40 & 97.65 & 0.90 \\
\cline { 2 - 4 } & 49.5 & 99.45 & 0.97 \\
\hline \multirow{3}{*}{$\begin{array}{c}\text { Column } \\
\text { temperature }\left({ }^{\circ} \mathrm{C}\right)\end{array}$} & 24 & 97.89 & 0.92 \\
\cline { 2 - 4 } & 25 & 98.32 & 0.83 \\
\cline { 2 - 4 } & 26 & 99.99 & 0.85 \\
\hline
\end{tabular}

temperature $\left( \pm 1^{\circ} \mathrm{C}\right)$, are within the limits that produce acceptable chromatography thereby being incorporated into the new method. Here the mean recoveries ranged from $97.65 \%$ to $100.10 \%$ with $\%$ RSD ranging from 0.83 to $0.97 \%$ (Table 4 ).

Results analyzed were statistically significant $(p<0.05)$. Moreover, retention times for melphalan and peak symmetry remained constant significantly with time and experimental conditions. Thus, method proposed for the determination of RP and RP-HPLC was reproducible and robust.

\section{Stability}

Here the HPLC method was tested by means of exposing samples of melphalan $\left(50 \mu \mathrm{g} \mathrm{mL} \mathrm{m}^{-1}\right)$ to sunlight (room temperature, $24 \mathrm{~h}$ ) and storage at freeze conditions for $24 \mathrm{~h}$ and 15 days. These experimental conditions were tested in order to reproduce conditions found in the preparation and manipulation of the lyophilized nanosuspension of melphalan. Samples were analyzed and 
were compared to freshly prepared standards and the results obtained confirmed the stability of melphalan. Under all the conditions, tested changes were found lower than $2 \%$ and no other peaks were appeared in the chromatograms (data not shown). Excellent separation was achieved indicating that the new method proposed remained selective for melphalan under the experimental conditions assayed.

\section{Specificity}

Three different samples of mannitol, blank lyophilized nanosuspension, blank lyophilized nanosuspension spiked with melphalan stock solution $\left(50 \mu \mathrm{g} \mathrm{mL} \mathrm{m}^{-1}\right)$ were prepared and then analyzed by the HPLC method using the extraction procedure of melphalan from nanosuspension. Before injection samples were diluted with mobile phase. Analysis of three solutions containing melphalan $\left(50 \mu \mathrm{g} \mathrm{mL}^{-1}\right)$ was performed in order to determine whether the method allows for the separation of melphalan from lyophilized nanosuspension. The chromatograms obtained for mannitol showed only one peak appearing at $2.783 \mathrm{~min}$. (Figure $4 \mathrm{a}$ ), while analysing blank lyophilized nanosuspension a well-defined peak was appeared at 2.783 which corresponds to mannitol (Figure 4b). The chromatograms obtained after analysis of lyophilized nanosuspension of melphalan, show the characteristic peaks of mannitol and melphalan (Figure 2). Finally, the chromatograms obtained for blank lyophilized nanosuspension spiked with a solution of melphalan $\left(50 \mu \mathrm{g} \mathrm{mL} \mathrm{L}^{-1}\right)$ (Figure $4 \mathrm{c}$ ) showed characteristic peaks of mannitol and melphalan with no other peaks eluting.
Extraction recovery and determination of melphalan entrapment efficiency from lyophilized nanosuspension

Fabrication of very slightly water-soluble or practically water insoluble drug substances to nanosuspension are of great demand due to consequences of the previously mentioned problems. ${ }^{16}$ Nanosuspension is a type of submicron colloidal dispersion, in which drug particles were dispersed in water with a surfactant or polymer as a stabilizer through broken preparation technology or self-assembly technology $y^{17-18}$ and has wide suitability for biopharmaceutical classification system classes II and IV drugs. ${ }^{19-21}$ Currently used nano suspension engineering processes are pearl milling, high-pressure homogenization either in water or in mixture of waters and water-miscible liquids or non-aqueous media and precipitation. ${ }^{22-25}$ Here nanosuspension of melphalan was developed to enhance its bioavailability and lyophilized to stabilize its particle size by preventing Ostwald ripening. The results obtained from method used for recovery of lyophilized nanosuspension showed that $15 \mathrm{~mL}$ of methanol is the most appropriate volume (Figure $5)$, with mean extraction recoveries of melphalan of $99.23 \%$ and $\%$ RSD lower than $2.0 \%$. Thus, data indicates that the extraction recoveries of melphalan were efficient, reproducible and consistent.

Thus, the proposed HPLC method was applied to quantify melphalan entrapped into the developed nanosuspension. The entrapment efficiency of melphalan from lyophilized nanosuspension was found to $93.56 \pm$

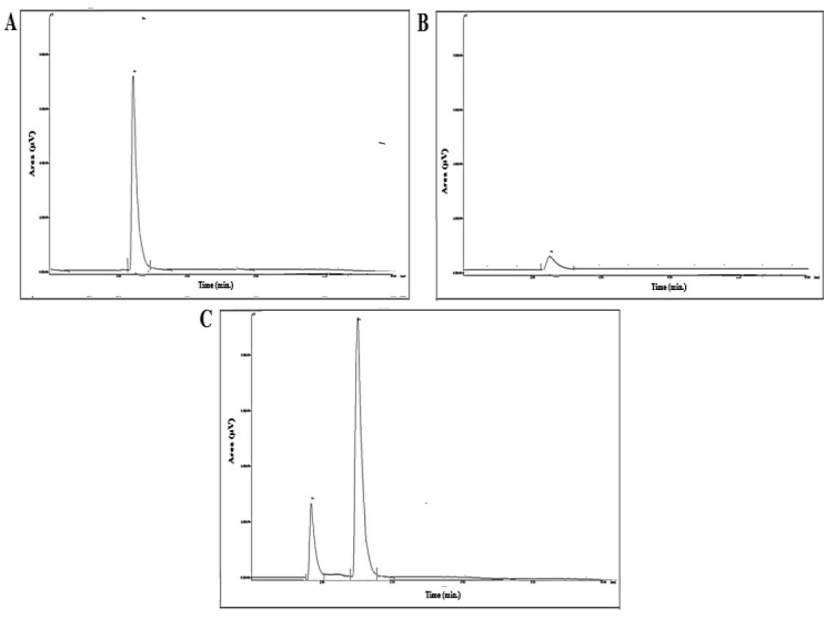

Figure 4: Chromatograms obtained for a) mannitol b) blank lyophilized nanosuspension $\mathrm{C}$ ) blank lyophilized nanosuspension spiked with melphalan $\left(50 \mu \mathrm{g} \mathrm{mL}^{-1}\right)$.

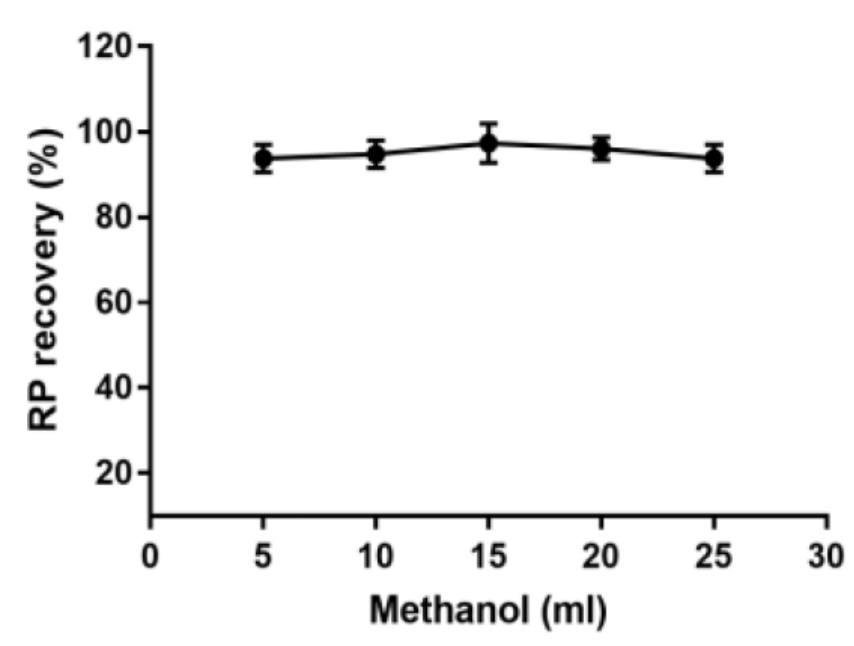

Figure 5: Extraction recoveries (\%) of melphalan from lyophilized nanosuspension versus methanol $(\mathrm{mL})$. 
$4.32 \%$ thus confirmed method is effective and rapid for this purpose.

\section{CONCLUSION}

The high-pressure homogenizer method was used to obtain lyophilized nanosuspension of melphalan to enhance its bioavailability and stability to treat ovarian cancer. A simple, easy, rapid and cost-efficient HPLC method with UV detection was developed and fully validated for quantification of melphalan. This method is suitable for analysis of drug in lyophilized nanosuspension. The HPLC method proposed presents short chromatographic runs $(<10 \mathrm{~min})$ and a very good resolution to detect both melphalan. Sensitivity, linearity, precision, accuracy and robustness of method developed were adequate; allowing analysis of melphalan from lyophilized nanosuspension, which was first described in this work for its quantitation that is useful for both in research and routine analysis. Moreover, the method allows simultaneous determination of melphalan, which could be administered orally with enhanced bioavailability in order to achieve the desired therapeutic level.

\section{ACKNOWLEGEMENT}

The authors are grateful to Dr. Babasaheb Ambedkar Research and Training Institute (BARTI), Pune for providing funding to carry out the research work.

\section{CONFLICT OF INTEREST}

The authors declare no conflicts of interest.

\section{ABBREVIATIONS}

HPLC: High performance liquid chromatography; RSD: relative standard deviation; LOD: Limit of detection; LOQ: Limit of quantitation; CV: Coefficients of Variation; RE: Relative error; ICH: International Conference on Harmonization.

\section{REFERENCES}

1. Kumar K, Nadh V. A validated RP-HPLC method for the estimation of melphalan in tablet dosage forms. Rasayan J Chem. 2011;4(4):863-7.

2. Rao KJ, Mohan M, Roa RM. Simaltaneous Determination of Melphalan and Its Process Related Impurities Using a Stability-Indicating and Validated Reverse Phase HPLC Method in a Short Run Time. Int Org Sci Res. 2017;12(5):69-78.

3. Bergel F, Stock JA. Cyto-active amino acid and peptide derivatives. Part I. Substituted phenylalanines. J Chem Soc. 1954;2409-17.
4. Malecki F, Sulkowska J, Weiss-Granzinska W. Reversed Phase High performance Liquid Chromatography analysis of melphalan in Pharmaceuticals. Chem Anal. 19931;38(2):255.

5. Kiran K, Nadh RV. A validated RP-HPLC method for the estimation of melphalan in tablet dosage forms. Rasayan J Chem. 2011;4(4):863-7.

6. Vishwanth G, Sunith P, Jyothi NC. Method development and validtion of melphalan injection by RP-HPLC method. J Pharm Biomed Ana Lett. 2015;3(1):224-7.

7. Rao J, Mohan M, Rao R. Simultaneous determination of melphalan and its process related impurities using a stability-indicating and validated reverse phase HPLC method in a short run time. J Pharm Bio Sci. 2017;5(1):69-78.

8. Brightman K, Finlay G, Jarvis I, Knowlton T, Manktelow CT. A stabilityindicating method for the determination of melphalan and related impurity content by gradient HPLC. J Pharm Biomed Ana. 1999;20(3):439-47.

9. Shanmugavel S, Karthikeyan V. Analytical method development and validation of layer by layer magnetic nanoparticles of methotrexate and melphalan. W J Pharm Pharma Sci . 2014;3(3):1221-53.

10. Hajare A, Powar T, Bhatia N, More H. Development and validation of RPHPLC method for determination of doxorubicin hydrochloride from vacuum foam dried formulation. Research J Pharm and Tech. 2016;9(9):1265-9.

11. Sun W, Mao S, Shi Y, Li CK, Fang L. Nanonization of itraconazole by highpressure homogenization: stabilizer optimization and effect of particle size on oral absorption. J Pharm Sci. 2011;100(8):3365-73.

12. Fuster J, Negro S, Salama A, Fernández-Carballido A, Marcianes P, Boeva L, et al. HPLC-UV method development and validation for the quantification of ropinirole in new plga multiparticulate systems: microspheres and nanoparticles. Int J Pharm. 2015;491(1-2):310-7.

13. Zhang H, Chen W, Zhao Z, Dong Q, Yin L, Zhou J, et al. Lyophilized nanosuspensions for oral bioavailability improvement of insoluble drugs: preparation, characterization and pharmacokinetic studies. J Pharm Innov. 2017;12(3):1-10.

14. Borhade V, Pathak S, Sharma S, Patravale V. Formulation and characterization of atovaquone nanosuspension for improved oral delivery in the treatment of malaria. Nanomedicine (Lond). 2014;9(5):649-66.

15. Shabir GA. Validation of high-performance liquid chromatography methods for pharmaceutical analysis: Understanding the differences and similarities between validation requirements of the US Food and Drug Administration, the US Pharmacopeia and the International Conference on Harmonization. J Chromatogr. 2003;987(1-2):57-66.

16. Lai F, Sinico C, Ennas G, Marongiu F, Marongiu G, Fadda AM. Diclofenac nanosuspensions: influence of preparation procedure and crystal form on drug dissolution behaviour. Int J Pharm. 2009;373(1-2):124-32.

17. Patel VR, Agrawal YK. Nanosuspension: An approach to enhance solubility of drugs. J Adv Pharm Technol Res. 2011;2(2):81-7.

18. Kesisoglou F, Panmai S, Wu Y. Nanosizing - Oral formulation development and biopharmaceutical evaluation. Adv Drug Deliv Rev. 2007;59(7):631-44.

19. Gao Y, Li Z, Sun M, Guo C, Yu A, Xi Y, et al. Preparation and characterization of intravenously injectable curcumin nanosuspension. Drug Deliv. 2011;18(2):131- 42.

20. Gao L, Liu G, Ma J, Wang X, Zhou L, Li X. Drug nanocrystals: In vivo performances. J Control Release. 2012;160(3):418-30.

21. Hao L, Wang $X$, Zhang $D, X u Q$, Song $S$, Wang $F$, et al. Studies on the preparation, characterization and pharmacokinetics of Amoitone $B$ nanocrystals. Int J Pharm. 2012;433(1-2):157-64.

22. Huang $Q, Y u H, R u Q$. Bioavailability and delivery of nutraceuticals using nanotechnology. J Food Sci. 2010;75(1):R50-7.

23. Müller RH, Peters K. Nanosuspensions for the formulation of poorly soluble drugs: I. Preparation by a size-reduction technique. Int J Pharm. 1998;160(2):229-37.

24. Maskarinec SA, Hannig J, Lee RC, Lee KY. Direct observation of poloxamer 188 insertion into lipid monolayers. Biophys J. 2002;82(3):1453-9.

25. Trotta M, Gallarate M, Pattarino F, Morel S. Emulsions containing partially water-miscible solvents for the preparation of drug nanosuspensions. J Control Release. 2001;76(1-2):119-28. 


\section{SUMMARY}

- In this present work the stability and amount of drug entrapped in lyophilized nanosuspension was determined by using simple, rapid, accurate HPLC-UV method. Melphalan is an anticancer drug used to treat ovarian cancer with poor bioavailability. Here nanosuspension of melphalan was developed to enhance its bioavailability by high-pressure homogenizer technique and lyophilized to stabilize its particle size by preventing Ostwald ripening. The analytical method was suitable for analysis of melphalan in lyophilized nanosuspension. This developed method employs Phenomenex $C^{18}(150 \mathrm{~nm} \times 4.6 \mathrm{~nm}$, i.d., $5 \mu \mathrm{m}$ particle size) a reversed phase analytical column as a stationary phase and acetic acid: methanol: water (1: 49.5: 49.5) adjusted to $\mathrm{pH} 4$ as a mobile phase. A run of $10 \mathrm{~min}$ was followed as a gradient programme. The method developed showed an intense peak of melphalan with retention time of $3.033 \mathrm{~min}$. As per ICH Q2R1 guidelines for precision, specificity, accuracy, linearity, limit of quantitation and limit of detection, the performance of HPLC method was validated. Stability studies of lyophilized nanosuspension was tested by means of exposing samples of melphalan $\left(50 \mu \mathrm{g} \mathrm{mL}{ }^{-1}\right)$ to sunlight (room temperature, $24 \mathrm{~h}$ ) and storage at freeze conditions for $24 \mathrm{~h}$ and 15 days. These experimental conditions were tested in order to reproduce conditions found in the preparation and manipulation of the lyophilized nanosuspension of melphalan. Excellent separation was achieved indicating that the new method proposed remained selective for melphalan under the experimental conditions assayed. The results obtained from method used for recovery of lyophilized nanosuspension showed that $15 \mathrm{~mL}$ of methanol is the most appropriate volume with mean extraction recoveries of melphalan of $99.23 \%$ and $\%$ RSD lower than $2.0 \%$. Thus, data indicates that the extraction recoveries of melphalan were efficient, reproducible and consistent. Thus, the proposed HPLC method was applied to quantify melphalan entrapped into the developed nanosuspension. The entrapment efficiency of melphalan from lyophilized nanosuspension was found to $93.56 \pm 4.32 \%$ thus confirmed method is effective and rapid for this purpose.

PICTORIAL ABSTRACT

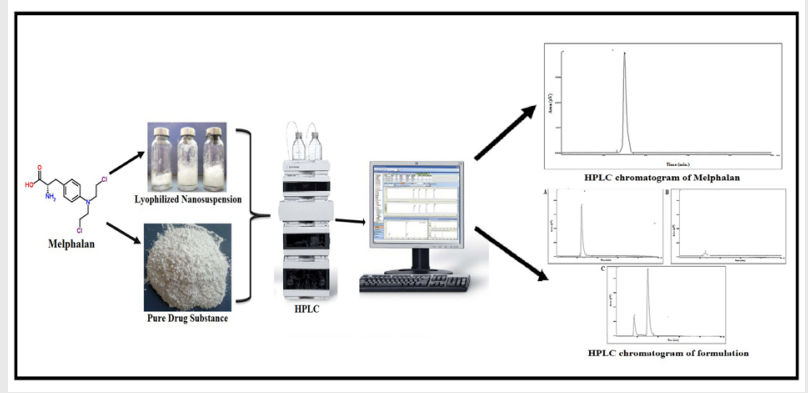

\section{ABOUT AUTHORS}

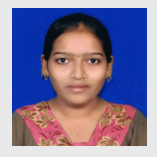

Ms. Powar Trupti Ashok is a Senior Research Fellow in Department of Pharmaceutics at Bharati Vidyapeeth College of Pharmacy, Kolhapur.

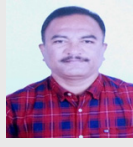

Dr. Hajare Ashok Ananda is working as a Professor in Department of Pharmaceutics at Bharati Vidyapeeth College of Pharmacy, Kolhapur.

Cite this article: Powar TA. Hajare AA. Development and Validation of an HPLC- UV Method for the Determination of Melphalan from Lyophilized Nanosuspension. Indian J of Pharmaceutical Education and Research. 2019;53(2):31624. 